\title{
A Solid and Robust Model for Xylitol Enzymatic Production Optimization
}

\section{Branco R. F ${ }^{1 *}$, Santos J. $C^{2}$ and Silva S.S}

${ }^{1}$ Federal Technological University of Paraná - Campus Pato Branco, Coordination Chemistry, Research Group in bioprocesses and food technology, Fraron, Pato Branco, Paraná, Brazil

2University of Sao Paulo - School of Engineering of Lorena, Department of Biotechnology, Group of Applied Microbiology and Bioprocess, Road of the city soccer field PO Box 116, Postal code 12602810, Lorena, SP, Brazil

\begin{abstract}
Xylitol production by fermentation process is widely studied. However, few works describes the enzymatic production of this polyalcohol. This works aims to determine a model that could explain the xylitol enzymatic production as a function of major variables in this process. For this purpose we applied an adequate statistical analysis and response surface methodology (RSM). Initially, variables were selected using a $2^{5-1}$ fractioned factorial design. Xylose and NADPH concentrations were chosen for the optimization experiments. In order to use the RSM, experiments according to a $2^{2}$ factorial design with star points and triplicate in the center were carried out. The statistical analysis resulted in a quadratic model which could explain $98.6 \%$ of the volumetric productivity in xylitol in function of xylose and NADPH concentrations. Using predicted experimental conditions of $7.0,25^{\circ} \mathrm{C}, 1.2 \mathrm{mM} \mathrm{NADPH}, 0.34 \mathrm{M} x y l o s e$, glucose $0.2 \mathrm{U} \mathrm{mg}^{-1}$ xylose reductase and $0.2 \mathrm{U} \mathrm{mg}^{-1}$ glucose dehydrogenase, this solid model was possible to achieve in batch reaction a xylitol volumetric productivity of $1.58 \pm 0.05 \mathrm{~g} \mathrm{~L}^{-1} \mathrm{~h}^{-1}$ with stoichiometric xylose/xylitol conversion efficiency. These values are considered higher and significant in comparing with the traditional fermentation processes. Our results contribute for development of a novel and promising alternative process for xylitol production.
\end{abstract}

Keywords: Multi-enzymatic process;experimental design; Coenzyme regeneration; Oxidoreductive enzymes

Nomenclature: ANOVA: Analysis of variance; CTAB: Cetyltrimethyl ammonium bromide ; DF: Degree of freedom; a: gravity acceleration $\left(9.8 \mathrm{~m} \mathrm{~s}^{-2}\right)$; MS: Mean of squares; NAD: Nicotinamide adenine dinucleotide; NADH: Reduced nicotinamide adenine dinucleotide; NADP: Nicotinamide adenine dinucleotide phosphate; NADPH: Reduced nicotinamide adenine dinucleotide phosphate; Qp: Xylitol volumetric productivity $\left(\mathrm{g} \mathrm{L}^{-1} \mathrm{~h}^{-1}\right)$; RSM: Response surface methodology; SQ: Sum of squares;TRIS:Tris(hydroxymethyl)aminomethane; $\mathrm{X}_{1}$ : Symbol for xylose concentration codified variable; $\mathrm{X}_{2}$ : Symbol for glucose concentration codified variable; $\mathrm{X}_{3}$ : Symbol for xylose reductase load codified variable; $\mathrm{X}_{4}$ : Symbol for glucose dehydrogenase load codified variable; $\mathrm{X}_{5}$ : Symbol for NADPH concentration codified variable; xi: Independent variable (factor) codified value; Xi: Independent variable (factor) real value; $\mathrm{X}_{0}$ : Central point real value; $\Delta \mathrm{Xi}$ : Step change value

\section{Introduction}

Xylitol is an important five carbon pentahydroxylated polyols with many significant applications in food, odontological and pharmaceutical industries. It stands out as a natural sweetener that does not cause and combats dental caries; it also prevents respiratory infections, among other properties [7-9]. This compound has been currently used, beside as sweetener, in tooth paste, gum, mouthwash and nasal spray.

Xylitol is produced traditionally by chemical means and many fermentation processes are under studies. However, the lower bioconversion rates are still a challenge to establish a feasible and low cost large scale technology. Thus, enzymatic reactions are novel biotechnological alternative for traditional microbiological and chemical production processes. In xylitol case, it is believed that the enzymatic way can surpass disadvantages of the chemical and microbiological routes, such as low conversion efficiency and productivity [1-3], being this new option also appropriate to current concepts and interests of sustainability and ecosystem preservation, for example the use of sugarcane bagasse as source of xylose and glucose $[4,5]$. In the enzymatic process it is possible to achieve, without difficulty, high productivity with stoichiometric conversion of xylose into xylitol process which would be very difficult in the fermentative and chemical batch processes [6]. Xylitol enzymatic production consists in the direct reduction of xylose into xylitol by the enzyme xylose reductase (E.C. 1.1.1.21) assisted, in this work, by the coenzyme nicotinamide adenine dinucleotide phosphate in its reduced form (NADPH). Further, the NADP can be reduced again in a coupling enzymatic reaction in order to minimize process cost. Here we used a glucose dehydrogenase system in which glucose is oxidized to gluconic acid (gluconate) mediated by glucose dehydrogenase (E.C. 1.1.1.119) and NADP is reduced to NADPH for the xylitol enzymatic production.

However, as a new procedure firstly it is necessary to determinate and to understand the influence and interactions of many variables involved on the enzymatic process before attempting to optimize it. In these cases, the experimental design methodology, or more specifically fractional factorial designs are indicated $[10,11]$. The search for a representative model of the process can represent an economic gain and allows the discovery and predicting ideal process conditions. Therefore, after the screening, the optimization can be performed also by experimental design using the response surface methodology (RSM), a very accurate method to maximize the desirable response variable [12-14].

In this context, the present work had as objective to optimize the enzymatic production of xylitol in batch regime using RSM and determine an adequate model to explain xylitol enzymatic production.

*Corresponding author: Branco R. F, Universidade Tecnológica Federal do Paraná - Campus Pato Branco, Coordenação de Química, Grupo de pesquisa em tecnologia de bioprocessos e alimentos Address: Via do Conhecimento km 01, Fraron, Pato Branco, Paraná, Brazil, Postal code 85503390; Tel: 55 (46) 3220 2596; E-mail: ricardobranco@utfpr.edu.br, ricardobranco@utfpr.edu.br

Received Spetember 16, 2011; Accepted November 12, 2011; Published November 16, 2011

Citation: Branco RF, Santos JC, Silva SS (2011) A Solid and Robust Model for Xylitol Enzymatic Production Optimization. J Bioprocess Biotechniq 1:108 doi: 10.4172/2155-9821.1000108

Copyright: (c) 2011 Branco RF, et al. This is an open-access article distributed under the terms of the Creative Commons Attribution License, which permits unrestricted use, distribution, and reproduction in any medium, provided the original author and source are credited. 
It must be highlighted that there are no records for this kind of approach for xylitol enzymatic production. The work was done in two parts; the first one was the screening of variables using a $2^{5-1}$ fractional factorial design with triplicate at central point, being xylitol volumetric productivity (Qp, $\left.\mathrm{g} \mathrm{L}^{-1} \mathrm{~h}^{-1}\right)$ the major response variable. The second step was the optimization of the process using a $2^{2}$ factorial design with star points and triplicate in the center in which the results were used for RSM. This work contributes with a consistent approach to study optimize a bioprocess.

\section{Material and Methods}

\section{Materials}

All chemicals used in this study were of the analytical grade available and were obtained from Sigma-Aldrich (São Paulo, Brazil), save the ones mentioned in the text.

\section{Preparation of xylose reductase pre-purified extract}

The xylose reductase pre-purified extract used in all assays was produced in-house. Pre-purification was required to separate xylose reductase from xylitol dehydrogenase in order to avoid xylitol consumption. The pre-purified xylose reductase extract used in the reactions was prepared in three steps: the yeast Candida guilliermondii FTI 20037 cultivation, cell disruption and reverse micelle technique. The first step, cell cultivation, was performed in a batch system in a BIOFLO III bioreactor of 1.25 L (New Brunswick Scientific Co. Inc., Edison, New Jersey, USA). The total fermentation media volume was $1.0 \mathrm{~L}$, containing 50 $\mathrm{g} \mathrm{L}^{-1}$ xylose, $3 \mathrm{~g} \mathrm{~L}^{-1}$ ammonium sulfate, $10 \% \mathrm{v} \mathrm{v}^{-1}$ rice bran extract, $0.1 \mathrm{~g} \mathrm{~L}^{-1}$ calcium chloride and $0.1 \% \mathrm{v} \mathrm{v}^{-1}$ antifoaming (silicone base, Adonex, São Paulo, Brazil). The $\mathrm{pH}$, dissolved oxygen and temperature were kept at $5.50 ; 50 \%$ and $30^{\circ} \mathrm{C}$, respectively. Initial cell concentration of Candida guilliermondii FTI 20037 was $1.0 \mathrm{~g} \mathrm{L-1}$ (dry weight) and the inoculum was prepared as described elsewhere [15]. The $\mathrm{pH}$ was controlled by addition of $3 \mathrm{M} \mathrm{NaOH}$. In the second step, the crude xylose reductase extract was obtained by the microbial cells disruption under vortex agitation using glass pearls $(0.5 \mathrm{~mm}$ diameter). The used conditions for the disruption were previously determined by [16]. Finally, the pre-purified xylose reductase extract was produced by reverse micelle technique using CTAB-reversed-micelles in isooctane, hexanol and butanol, by a two-step procedure according methodology described in our laboratory [17]. Firstly, $3.0 \mathrm{ml}$ of the crude extract was mixed with an equal volume of micellar microemulsion (CTAB in isooctane/ hexanol/butanol/water). This mixture was agitated on a vortex for 1 min, to obtain the equilibrium phase, and separated into two phases by centrifugation at 6570 a for $10 \mathrm{~min}$ (Jouan Centrifuge model 1812, Saint-Herblain, France). Afterwards, $2.0 \mathrm{~mL}$ of CTAB-micellar phase was mixed with $2.0 \mathrm{~mL}$ of fresh aqueous phase (acetate buffer $1.0 \mathrm{M}$ at pH 5.5 with $1.0 \mathrm{M} \mathrm{NaCl}$ ), in order to transfer xylose reductase from the micelles to this fresh aqueous which was finally collected by centrifugation (6570 a; $10 \mathrm{~min})$.

\section{Enzymes activity assays}

Xylose reductase activity was determined by spectrophotometric analysis using NADPH as the detecting parameter at $25^{\circ} \mathrm{C}$ and $340 \mathrm{~nm}$, in a medium composed of : $350 \mu \mathrm{L}$ Tris buffer $(71 \mathrm{mM}, \mathrm{pH} 7.2), 50 \mu \mathrm{L}$ NADPH (1.2 mM), $50 \mu \mathrm{L}$ xylose $(2.0 \mathrm{M})$ and $150 \mu \mathrm{L}$ of the enzymatic extract. The glucose dehydrogenase activity was also determined by spectrophotometric analysis using the same conditions. The medium was composed of $350 \mu \mathrm{L}$ Tris buffer (71 mM, pH 7.2), $50 \mu \mathrm{L}$ NADP (1.2 $\mathrm{mM}), 50 \mu \mathrm{L}$ glucose $(1.5 \mathrm{M})$ and $150 \mu \mathrm{L}$ of the enzymatic extract. Variation of the absorbance at $340 \mathrm{~nm}$ of the assay against a blank without enzyme was monitored for $1 \mathrm{~min}$. The activity was calculated from the slope of the absorbance versus the time curve by using the apparent molar extinction coefficient of $6.22 \mathrm{mmol}^{-1} \mathrm{~cm}^{-1}$ for NAD(P)H. One xylose reductase or glucose dehydrogenase unit (U) was defined as the amount of enzyme catalyzing the formation or degradation of $1 \mu \mathrm{mol}$ of NADPH per min. The volumetric activity was expressed as $\mathrm{U} \mathrm{mL}^{-1}$ (extract volume).

\section{Xylitol enzymatic production}

The enzymatic reactions were carried out in a $10 \mathrm{~mL}$ flask and a total reaction volume of $5 \mathrm{~mL}$ agitated by magnetic stirrer. In all assays the temperature and $\mathrm{pH}$ were kept at $25^{\circ} \mathrm{C}$ and 7.0 , respectively. The $\mathrm{pH}$ was controlled by addition of $0.2 \mathrm{M}$ Tris. The temperature and $\mathrm{pH}$ were controlled using the BIOFLO III bioreactor module (New Brunswick Scientific Co. Inc., Edison, New Jersey, USA). The other experimental conditions were varied according to the 25-1 and 22 designs.

\section{Experimental designs for model development}

Two experimental designs to achieve the optimization of xylitol enzymatic production were performed. A $2^{5-1}$ fractional factorial design with triplicate at center point, in a total of 19 assays, was used in order to select and evaluate the effect of five independent variables: xylose concentration, glucose concentration, NADPH concentration, xylose reductase load and glucose dehydrogenase load on xylitol enzymatic production. The study range was defined in previous experiments. The next step was the process optimization experiments which were performed according to a $2^{2}$ experimental design with star points and triplicate at center point. The factors selected for this design were xylose and NADPH concentrations, all the others factors were kept at the low level $(-1)$ of the first design $\left(2^{5-1}\right)$. For appropriate statistical analysis, the variables, of both experimental designs, needed to be coded according to Equation 1.

$$
x_{i}=\frac{X_{i}-X_{0}}{\Delta X_{i}}
$$

xi: independent variable (factor) coded value; $\mathrm{X}_{\mathrm{i}}$ : independent variable (factor) real value, $\mathrm{X}_{0}$ central point real value and; $\Delta \mathrm{X}_{\mathrm{i}}$ : step change value.

The range and levels investigated for the $2^{5-1}$ and the $2^{2}$ designs are presented in Table 1 and 2, respectively. Qp was the dependent variable (response) considered for selection and optimization. Both designs were proposed according to literature $[18,19]$. The statistical calculi were performed using the software STATISTICA (version 6.0, StatSoft, U.S.A.) and DESIGN EXPERT (version 6.0, Stat-Ease, U.S.A).

\section{Analytical methods}

Xylose and xylitol concentrations were determined by high performance liquid chromatography (HPLC) using Waters equipment (Waters, Milford, MA, USA) with a refractive index (RI) detector (model 2414, Waters, Milford, MA, U.S.A.), UV detector (model 2487, Waters, Milford, MA, U.S.A.) and a HPX-87H column (Bio-Rad, Hercules, CA, U.S.A.). The operational conditions were: temperature of $45^{\circ} \mathrm{C}, 0.005$ $\mathrm{M}$ sulfuric acid as eluent, flow of $0.6 \mathrm{~mL} \mathrm{~min} \mathrm{~m}^{-1}$ and injection volume of $20 \mu \mathrm{L}$. 


\begin{tabular}{|l|c|c|c|c|}
\hline \multirow{2}{*}{ Independent variables } & \multirow{2}{*}{ Symbol } & \multicolumn{3}{|c|}{ Range and levels } \\
\cline { 3 - 5 } & & -1 & 0 & 1 \\
\hline Xylose concentration $(\mathrm{M})$ & $\mathrm{X}_{1}$ & 0.033 & 0.066 & 0.100 \\
\hline Glucose concentration $(\mathrm{M})$ & $\mathrm{X}_{2}$ & 0.033 & 0.066 & 0.100 \\
\hline Xylose reductase load $\left(\mathrm{U} \cdot \mathrm{mL}^{-1}\right)$ & $\mathrm{X}_{3}$ & 0.20 & 0.40 & 0.60 \\
\hline Glucose reductase load $\left(\mathrm{U} \cdot \mathrm{mL}^{-1}\right)$ & $\mathrm{X}_{4}$ & 0.20 & 0.40 & 0.60 \\
\hline NADPH concentration $(\mathrm{mM})$ & $\mathrm{X}_{5}$ & 0.20 & 0.40 & 0.60 \\
\hline
\end{tabular}

Table 1: Study range and levels with real values of the independent variables used for the 25-1 experimental design carried out to select and evaluate variables on the performance of the batch xylitol enzymatic production.

\begin{tabular}{|l|c|c|c|c|c|c|}
\hline \multirow{2}{*}{ Independent variables } & \multirow{2}{*}{ Symbol } & \multicolumn{5}{|c|}{ Range and levels } \\
\cline { 3 - 7 } & & $-\sqrt{ } 2$ & -1 & 0 & 1 & $\sqrt{ } 2$ \\
\hline Xylose concentration (M) & $\mathrm{X} 1$ & 0.039 & 0.100 & 0.250 & 0.400 & 0.460 \\
\hline NADPH concentration (mM) & $\mathrm{X} 5$ & 0.23 & 0.60 & 1.50 & 2.40 & 2.80 \\
\hline
\end{tabular}

Table 2: Study range and levels with real values of the independent variables used for the 22 experimental design carried out to optimize the batch xylitol enzymatic production.

\begin{tabular}{|c|c|c|c|c|c|c|}
\hline \multirow{2}{*}{ Assay } & \multicolumn{7}{|c|}{ Coded variable } & Response \\
\cline { 2 - 7 } & $\mathrm{X}_{1}$ & $\mathrm{X}_{2}$ & $\mathrm{X}_{3}$ & $\mathrm{X}_{4}$ & $\mathrm{X}_{5}$ & $\mathrm{Qp}^{*}\left(\mathrm{~g} \mathrm{~L}^{-1} \mathrm{~h}^{-1}\right)$ \\
\hline 1 & -1 & -1 & -1 & -1 & 1 & 0.46 \\
\hline 2 & 1 & -1 & -1 & -1 & -1 & 0.36 \\
\hline 3 & -1 & 1 & -1 & -1 & -1 & 0.20 \\
\hline 4 & 1 & 1 & -1 & -1 & 1 & 0.72 \\
\hline 5 & -1 & -1 & 1 & -1 & -1 & 0.43 \\
\hline 6 & 1 & -1 & 1 & -1 & 1 & 0.57 \\
\hline 7 & -1 & 1 & 1 & -1 & 1 & 0.53 \\
\hline 8 & 1 & 1 & 1 & -1 & -1 & 0.35 \\
\hline 9 & -1 & -1 & -1 & 1 & -1 & 0.45 \\
\hline 10 & 1 & -1 & -1 & 1 & 1 & 0.87 \\
\hline 11 & -1 & 1 & -1 & 1 & 1 & 0.52 \\
\hline 12 & 1 & 1 & -1 & 1 & -1 & 0.89 \\
\hline 13 & -1 & -1 & 1 & 1 & 1 & 0.38 \\
\hline 14 & 1 & -1 & 1 & 1 & -1 & 0.48 \\
\hline 15 & -1 & 1 & 1 & 1 & -1 & 0.35 \\
\hline 16 & 1 & 1 & 1 & 1 & 1 & 1.20 \\
\hline 17 & 0 & 0 & 0 & 0 & 0 & 0.89 \\
\hline 18 & 0 & 0 & 0 & 0 & 0 & 0.88 \\
\hline 19 & 0 & 0 & 0 & 0 & 0 & 0.90 \\
\hline
\end{tabular}

*correspondent to $6 \mathrm{~h}$ of reaction

Table 3: $2^{5-1}$ experimental design matrix with correspondent $Q p$ results for each assay.

\begin{tabular}{|c|c|c|c|c|}
\hline Term & Effect value & Standard error & $\mathrm{t}$-value (13 DF) & $\mathrm{p}$-value \\
\hline Average & 0.60 & 0.055 & 12.0 & $<0.01$ \\
\hline $\mathrm{X}_{1}$ & 0.26 & 0.110 & 2.4 & 0.03 \\
\hline $\mathrm{X}_{2}$ & 0.09 & 0.110 & 0.8 & 0.42 \\
\hline $\mathrm{X}_{3}$ & -0.02 & 0.110 & -0.2 & 0.81 \\
\hline $\mathrm{X}_{4}$ & 0.18 & 0.110 & 1.7 & 0.11 \\
\hline $\mathrm{X}_{5}$ & 0.21 & 0.110 & 2.0 & 0.07 \\
\hline
\end{tabular}

*DF: Degree of freedom; $t$ - tabulated $= \pm 1.77$ for a confidence level of $90 \%$ and 13 DF.

Table 4: Effect values and significance tests for the average and main variables effects in relation to $\mathrm{Qp}$ for the $2^{5-1}$ experimental design.

\section{Results and Discussion}

\section{Screening of major variables for enzymatic xylitol production model}

Amongst the variables which influence the catalytic activity of en- zymes it were selected for the study of xylitol enzymatic production: xylose concentration, glucose concentration, NADPH concentration, xylose reductase load and glucose dehydrogenase load. The data for analysis of influence and screening of those variables was generated by experiments to a $25^{-1}$ fractioned factorial design, with triplicate at center point. The design matrix with the volumetric productivity in xylitol $\left(\mathrm{Qp}, \mathrm{g} \mathrm{L}^{-1} \mathrm{~h}^{-1}\right)$ for each assay are presented in Table 3. The results were input in the software STATISTICA (6.0), for determining the main effect values and to carry out significance tests, which are presented in Table 4.

The observed Qp values (Table 3), demonstrating that the chosen study region was adequate, since it varied between 0.20 and $1.20 \mathrm{~g} \mathrm{~L}^{-1}$ $\mathrm{h}^{-1}$ showing an adequate range. The center point triplicate evidenced that the experiments were reproducible, once the standard error was lower than 0.01 . In relation to the NADPH regeneration system (glucose dehydrogenase), the results demonstrated that it worked satisfactorily with the main reaction, once it was not observed the formation of by-products (side reactions) and in all experiments the xylose-xylitol conversion efficiency was stoichiometric.

The statistical analysis demonstrated that only the effect of xylose and NADH concentrations were significant, at a $90 \%$ confidence level (Table 4). Both effects were positive indicating that the response (Qp) benefits by the use of these factors at their superior levels $(+1)$ the influence of these factor can be observed by the results in Table 3, specially in assays 15 and 16. In assay number 15 xylose and NADPH concentrations were used at their inferior levels $(-1)$ as result the $Q p$ value was low $\left(0.35 \mathrm{~g} \mathrm{~L}^{-1} \mathrm{~h}^{-1}\right)$, however when they were used at their superior level $(+1)$, assay number 16 , it was observed the highest Qp value $(1.20 \mathrm{~g}$ $\left.\mathrm{L}^{-1} \mathrm{~h}^{-1}\right)$, three times higher than assay 15 . This result demonstrated that the main reaction rate was elevated with the increase of the substrates concentrations, xylose and NADPH, independent of the enzyme xylose reductase amount. This fact indicates that, probably, the reaction rate could be raised if the concentrations of xylose and NADPH were further increased. Thus it was necessary, for the process optimization, a new study range for these variables since they were still in non-limiting concentrations.

Therefore, the concentrations of xylose and NADPH were the factors selected for the study of xylitol enzymatic production optimization and for the development of a mathematical model in batch, being a new study range defined in which the concentrations were increased.

\section{Process optimization using RSM and model development}

This work aimed to optimize the enzymatic production of xylitol in batch regime using RSM and to determine an empiric model.

It was selected for xylitol enzymatic production optimization and to develop a statistical model, the concentrations of xylose and NADPH. The experiments were carried out according to a $2^{2}$ complete factorial design, with star points and triplicate at center point. The design matrix and Qp result for each assay are presented in Table 5. For effects significance tests, analysis of variance (ANOVA) of the model, regression coefficients determination and RSM the data were input in the software STATISTICA and DESIGN EXPERT.

The results presented in Table 5 demonstrated that the shift on the study range benefited productivity, since the mean $\mathrm{QP}$ value, compared to the first design, increased from 0.60 to $1.42 \mathrm{~g} \mathrm{~L}^{-1} \mathrm{~h}^{-1}, 2.4$ times higher. The best $\mathrm{Qp}$ value $\left(1.63 \mathrm{~g} \mathrm{~L}^{-1} \mathrm{~h}^{-1}\right)$ was observed at assay 10 (Table 5), which is a replicate at center point, this result indicated that this region is, probably, near the maximum for Qp. 
Citation: Branco RF, Santos JC, Silva SS (2011) A Solid and Robust Model for Xylitol Enzymatic Production Optimization. J Bioprocess Biotechniq 1:108 doi: 10.4172/2155-9821.1000108

Page 4 of 6

\begin{tabular}{|c|c|c|c|}
\hline \multirow{2}{*}{ Assay } & \multicolumn{2}{|c|}{ Coded variable } & Response \\
\cline { 2 - 4 } & $\mathrm{X}_{1}$ & $\mathrm{X}_{5}$ & $\mathrm{Qp}^{*}\left(\mathrm{~g} \mathrm{~L}^{-1} \mathrm{~h}^{-1}\right)$ \\
\hline 1 & -1 & -1 & 1.03 \\
\hline 2 & 1 & -1 & 1.40 \\
\hline 3 & -1 & 1 & 1.33 \\
\hline 4 & 1 & 1 & 1.51 \\
\hline 5 & $-\sqrt{2}$ & 0 & 1.20 \\
\hline 6 & $+\sqrt{2}$ & 0 & 1.12 \\
\hline 7 & 0 & $-\sqrt{2}$ & 1.61 \\
\hline 8 & 0 & $+\sqrt{2}$ & 1.52 \\
\hline 9 & 0 & 0 & 1.59 \\
\hline 10 & 0 & 0 & 1.66 \\
\hline 11 & 0 & 0 & 1.63 \\
\hline
\end{tabular}

ized in Figure 1, which presents the predicted data from the model in function of the experimental data.

After the significance confirmation of the empiric model, it was performed the optimization of the process using RSM. The response surface and contour curves are presented in Figure 2. According to Figure $2 \mathrm{a}$ and $2 \mathrm{~b}$ the increase in both variables (xylose and NADPH concentrations) brings benefit to productivity probably due to an increase in the main catalysis rate (xylitol production) since the substrates of the enzyme xylose reductase are increased and consequently its xylose to xylitol conversion rate, as predicted in traditional enzyme kinetic models.

The mathematic resolution of the model pointed a maximum Qp

*correspondent to $6 \mathrm{~h}$ of reaction

Table 5: $2^{2}$ experimental design matrix with correspondent Qp results for each assay.

\begin{tabular}{|l|l|l|l|l|}
\hline Term & Effect value & Standard error & $t$-value (2 DF) & $p$-value \\
\hline Average & 1.63 & 0.020 & 80.2 & $<0.01$ \\
\hline$X_{1}$ & 0.12 & 0.012 & 10.0 & $<0.01$ \\
\hline$X_{12}$ & -0.12 & 0.015 & -8.4 & 0.01 \\
\hline$X_{5}$ & 0.14 & 0.012 & 11.4 & $<0.01$ \\
\hline$X_{52}$ & -0.17 & 0.015 & -11.8 & $<0.01$ \\
\hline$X_{1} \cdot X^{5}$ & -0.06 & 0.018 & -3.3 & 0.08 \\
\hline
\end{tabular}

t- tabulated $= \pm 2.92$ for a $90 \%$ confidence level and 2 DF.

Table 6: Coefficient regression values and respective significance tests.

\begin{tabular}{|c|c|c|c|c|c|}
\hline Source of variation & $\mathrm{SS}^{*}$ & $\mathrm{DF}$ & $\mathrm{MS}^{* *}$ & $\mathrm{~F}-$ value & $\mathrm{p}-$ value \\
\hline Regression & 0.50 & 5 & 0.10 & 60.0 & $<0.01$ \\
\hline Residues & 0.01 & 5 & 0.02 & - & - \\
\hline Total & 0.51 & 10 & - & - & - \\
\hline Lack of fit & 0.006 & 3 & 0.002 & 1.6 & 0.42 \\
\hline Pure error & 0.002 & 2 & 0.001 & - & - \\
\hline \% of explained variation: 98.6 & & & \\
\hline
\end{tabular}

* SS: sum of squares ** MS: mean of squares. F - tabulated $=5.05$ for a confidence level of $95 \%, 5 \mathrm{DF}$ of the regression and $5 \mathrm{DF}$ of the residues.

Table 7: Analysis of variance (ANOVA) and variation values of the proposed quadratic model.

After the decision to keep all the regression terms, it was initiated the RSM which involves calculi and significant analysis of a quadratic empiric model.

The regression coefficients for each term in the quadratic model with their respective significance test are presented in Table 6 . The analysis of variance (ANOVA) of the quadratic model is presented in Table 7.

As can be observed in Table 6 all regression coefficients were significant and according to the ANOVA of the quadratic model (Table 7) the proposed model is adequate to explain the behavior of Qp in function of xylose concentration and NADPH concentration, in the study region, since the lack of fit was not significant (Table 7). The quadratic model (real values) is presented in Equation 2.

$$
\begin{aligned}
& \mathrm{Qp}=0.20+4.22[\text { Xylose }]-5.51[\text { Xylose }]^{2}+0.91[\mathrm{NADPH}]-0.21 \\
& {[\mathrm{NADPH}] 2-0.43[\text { Xylose]. [NADPH] }}
\end{aligned}
$$

The model could explain $98.6 \%$ of the experimental variation (Tabfle ), which means that it is solid and robust. This fact can be visual-

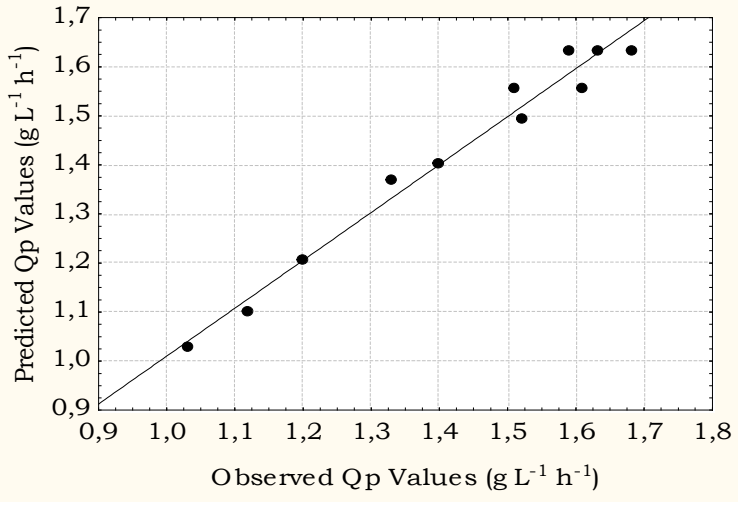

Figure 1: Observed $Q p$ values as a function of the predicted by the quadratic model. The curve represents the model and the dots are the experimental data.

a)
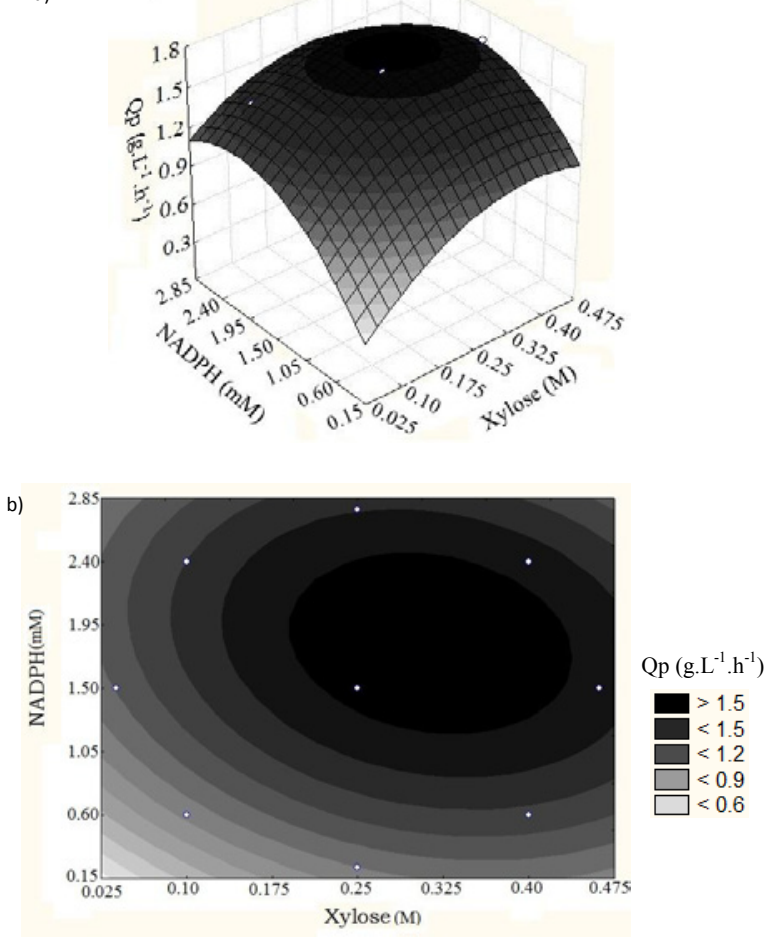

Figure 2: a) Response surface for xylitol volumetric productivity ( $Q p)$ as a function of xylose and NADPH concentrations (coded) and b) Contour curves. 


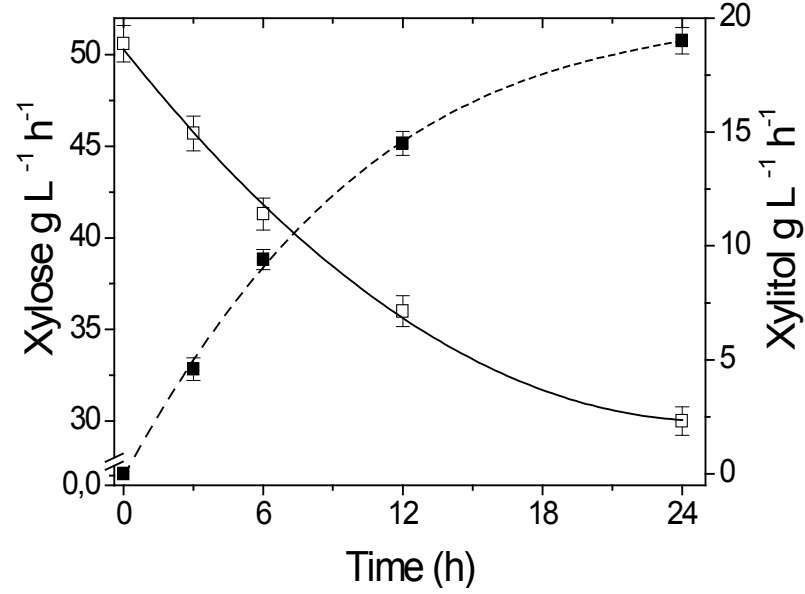

Figure 3: Xylose (solid square) and xylitol (blank square) concentrations as a function of reaction time for the optimized experimental condition: Xylose concentration $0.34 \mathrm{M}$ and NADPH concentration $1.2 \mathrm{mM}$.

value of $1.68 \mathrm{~g} \mathrm{~L}^{-1} \mathrm{~h}^{-1}$, referent to the coordinates $0.31 \mathrm{M}$ for xylose concentration and $1.80 \mathrm{mM}$ for NADPH concentration. This result surpasses the $Q p$ values and conversion values of literature for xylitol microbial production, in batch and with synthetic media $[20,21]$ which were 1.50 $\mathrm{g} \mathrm{L}^{-1} \mathrm{~h}^{-1}$ and $\quad 71 \%$ of xylose-xylitol conversion efficiency. However, it must be considered, even in earlier steps the process economics, in xylitol enzymatic production case the cost of the coenzyme NADPH is one of the greatest contributors for the total cost [22], hence is desirable a lower NADPH concentration since there is no important loss in productivity. In this context, in Figure $2 \mathrm{a}$ and $2 \mathrm{~b}$, it can be observed a wide region that comprehends an equal or higher Qp value of $1.60 \mathrm{~g}$ $\mathrm{L}^{-1} \mathrm{~h}^{-1}$, confirming also the robustness of the process, which is already a superior value from mentioned literature. Therefore, this region corresponding to a Qpvalue of $1.60 \mathrm{~g} \mathrm{~L}^{-1} \mathrm{~h}^{-1}$ was selected for optimization. Both mathematical and graphical resolutions, given by the softwares used, demonstrated that the minimum NADPH concentration which is needed to achieve this goal is $1.20 \mathrm{mM}$, with a corresponding concentration of xylose of $0.34 \mathrm{M}$. This NADPH concentration corresponds to a $33.3 \%$ reduction when compared to the concentration of $1.80 \mathrm{mM}$ pointed by the mathematical resolution to attain the maximum Qp value, mentioned earlier, $\left(1.68 \mathrm{~g} \mathrm{~L}^{-1} \mathrm{~h}^{-1}\right)$ and this reduction represents only in a Qp loss of only $5 \%$ (from 1.68 to $1.60 \mathrm{~g} \mathrm{~L}^{-1} \mathrm{~h}^{-1}$ ).

Therefore, it was carried out the model validation in those conditions, $1.20 \mathrm{mM}$ NADPH concentration and $0.34 \mathrm{M}$ xylose concentration, in duplicate. The experiments resulted in a $\mathrm{Qp}$ mean value of $1.58 \pm 0.05 \mathrm{~g} \mathrm{~L}^{-1} \mathrm{~h}^{-1}$, which is inside of the confidence statistical limits for this model. Xylose and xylitol concentrations in function of reaction time for these experiments are presented in Figure 3.

Xylitol is produced in the same rate as xylose consumption until the reaction reaches 6 hours (Figure 3). From this point, these rates gradually fall and from 24 hours the production almost ceases. This phenomenon is probably due to the depletion of glucose, which deactivates the coenzyme regeneration system therefore, reducing xylitol production.

\section{Conclusion}

The results presented in this work made possible to firstly selected adequate variables from a group, xylose and NADPH concentrations, using experimental design for further optimization. The optimization step was performed successfully using RSM and experimental design. It was possible to generate an empiric quadratic model which could explain the xylitol productivity in function of the studied variables. From predicted coordinates, $1.20 \mathrm{mM}$ NADPH concentration and $0.34 \mathrm{M}$ xylose concentration, the model was validated and it was possible to achieve a productivity of $1.58 \pm 0.05 \mathrm{~g} \mathrm{~L}^{-1} \mathrm{~h}^{-1}$ with stoichiometric xylose/ xylitol conversion efficiency. The results attained were higher when compared to the ones presented in literature for other xylitol production processes, in batch regime. The work also presented a potential process of xylitol enzymatic production as an alternative of traditional xylitol ways of production. Finally, it was possible to achieve a representative statistical model for xylitol enzymatic production which contributed to enlighten and improve this process.

\section{Acknowledgements}

The authors gratefully thank the financial support of the Fundação de Amparo à Pesquisa do Estado de São Paulo, FAPESP (Proc. $n{ }^{\circ}$ 05/0280-4 and 05/028669).

\section{References}

1. Alanem P, Isokangas $P$, Gutmann K (2000) Xylitol candies in caries prevention: results of a field study in Estonian children community. Dent Oral Epidemiol 28: 218-224.

2. Gliemmo MF, Calvin AM, Tamasib O, Gerschensona LN, Camposa CA (2008) Interactions between aspartame, glucose and xylitol in aqueous systems containing potassium sorbate. LWT - Food Sci Technol 41: 611-619.

3. Makinen KK (2000) Can the pentitol-hexitol theory explain the clinical observations made with xylitol. Med Hypothe 200: 603-613.

4. Santos JC, Mussatto SI, Dragone G, Converti A, Silva SS (2005) Evaluation of porous glass and zeolite as cells carriers for xylitol production from sugarcane bagasse hydrolysate. Biochem Eng J 23: 1-9.

5. Mikkola JP, Salmi T, Villela A, Vainio H, Mäki-Arvela P,et al. (2003) Hydrogenation of xylose to xylitol on sponge nickel catalyst - a study of the process and catalyst deactivation kinetics. Brazilian J Chem Eng 20: 263-265.

6. Marton JM, Felipe MGA, Silva JBA, Pessoa Jr A (2006) Evaluation of the activated charcoals and adsorption conditions used in the treatment of sugarcane bagasse hydrolysate for xylitol production. Brazilian J Chem Eng 23: 9-10

7. Gurpilhares DB, Hasmann FA, Pessoa Jr A, Roberto IC (2009) The behavior of key enzymes of xylose metabolism on the xylitol production by Candida guilliermondii grown in hemicellulosic hydrolysate. J Ind Microbiol Biotechnol 36: 87-93.

8. Sarrouh BF, Branco RF, Silva SS (2009) Production of Xylitol: Enhancement of Monosaccharide Biotechnological Production by Post-Hydrolysisof Dilute Acid Sugarcane Hydrolysate. Appl Biochem Biotechnol 153: 163-170.

9. Converti A, Torre P, Luca E, Perego P, Borghi M, et al. (2003) Continuous xylito production from synthetic xylose solutions by Candida guilliermondii: Influence of $\mathrm{pH}$ and temperature. Eng Life Sci 3: 193-198.

10. Neto BB, Scarmínio IS, Bruns RE (2007) Como fazer experimentos: pesquisa e desenvolvimento na ciência e na indústria. UNICAMP Press.

11. Rodrigues MI, Lemma AF (2005) Planejamento e otimização de processos: uma estrategia sequencial de planejamento Casa do Pão Press.

12. Branco RF, Santos JC, Murakami LY, Mussatto SI, Dragone G, Silva SS (2007) Xylitol production in a bubble column bioreactor: Influence of the aeration rate and immobilized system concentration. Process Biochem 42: 258-262.

13. Sharma S, Malik A (2009) Application of response surface methodology (RSM) for optimization of nutrient supplementation for $\mathrm{Cr}(\mathrm{VI})$ removal by Aspergillus lentulus AML05. J Hazard Mater 164: 1198-1204.

14. Sarrouh BF, Silva SS (2010) Application of Response Surface Methodology for Optimization of Xylitol Production from Lignocellulosic Hydrolysate in a Fluidized Bed Reactor. Chem Eng Tech 33: 1481-1487.

15. Branco RF, Silva SS (2010) Contribution of Tris Buffer on Xylitol Enzymatic Production. Appl Biochem Biotechnol 162: 1558-1563.

16. Gurpilhares DB, Pessoa Jr A, Roberto IC (2006) Glucose-6-phosphate dehy- 
Citation: Branco RF, Santos JC, Silva SS (2011) A Solid and Robust Model for Xylitol Enzymatic Production Optimization. J Bioprocess Biotechniq 1:108 doi: $10.4172 / 2155-9821.1000108$

drogenase and xylitol production by Candida guilliermondii FTI 20037 using statistical experimental design. Process Biochem 41: 631-637.

17. Cortez EV, Pessoa Jr A, Felipe MGA, Roberto IC, Vitolo M (2004) Optimized extraction by cetyl trimethyl ammonium bromide reversed micelles of xylose reductase and xylitol dehydrogenase from Candida guilliermondii homogenate. J Chromatography B 807: 47-54.

18. Box EPG, Hunter WG, Hunter JS (1978) Statistics for Experimenters: An Introduction to Design, Data Analysis, and Model Building. John Wiley \& Sons Press.

19. Box EPG, Hunter WG, Hunter JS (2005) Statistics for Experimenters: Design, Innovation, and Discovery. John Wiley \& Sons Press.
20. Branco RF, Santos JC, Sarrouh BF, Rivaldi JD, Pessoa Jr A, et al. (2009) Profiles of xylose reductase, xylitol dehydrogenase and xylitol production under different oxygen transfer volumetric coefficient values. J Chem Technol Biotechnol 84: 326-330.

21. Sampaio FC, Faveri D, Mantovani HC, Passos FML, Perego P, et al. (2006) Use of response surface methodology for optimization of xylitol production by the new yeast strain Debaryomyces hansenii UFV-170. J Food Eng 76: 376386.

22. Nidetzky B, Neuhauser W, Haltrich D, Kulbe KD (1996) Continuous enzymatic synthesis of xylitol with simultaneous coenzyme regeneration in a charged membrane reactor. Biotechnol Bioeng 52: 387-396. 